\title{
PASSIFLORACEAE DO BRASIL: ESTUDO DO GÊNERO Passiflora L. SUBGÊNERO Distephana (JUSS.) KILUIP.
}

\section{Brazilian Passifloraceae: Study of the subgenus Distephana (Juss.) Killip of the genus Passiflora L.}

\author{
Armando Carlos Cervi ${ }^{1}$ \\ Antônio Dunaiski Junior ${ }^{2}$
}

\section{Resumo}

Este trabalho é um estudo taxonômico das espécies de Passiflora L. que compõem o subgênero Distephana (Juss.) Killip, do Brasil. Este subgênero está representado por dez espécie: Passiflora araujoi Sacco; P. coccinea Aubl.; P. glandulosa Cav.; P. involucrata (Mast.) A.H.Gentry; P. quadrifaria Vanderplank; P. quadriglandulosa Rodschied; P. speciosa Gardner; P. tholozanii Sacco; P. variolata Poepp. \& Endl. e P. vitifolia Kunth. É apresentado chave de identificação das espécies, descrições, distribuição geográfica, observações ecológicas, dados fenológicos, etimologia e ilustrações dos táxons estudados.

Palavras-chave: Passifloraceae; Passiflora; Taxonomia, Subgênero Distephana; Brasil.

\section{Abstract}

This work is a taxonomic study of the Passiflora species of subgenus Distephana (Juss.) Killip from Brazil. This subgenus is represented by ten species: Passiflora araujoi Sacco; P. coccinea Aubl.; P. glandulosa Cav.; P. involucrata (Mast.) A. H. Gentry; P. quadrifaria Vanderplank; P. quadriglandulosa Rodschied; P. speciosa Gardner; P. tholozanii Sacco; P. variolata Poepp. \& Endl. and P. vitifolia Kunth. Identification keys of this species, descriptions, ecological observation, fenological data, etymology and geographical distribution of the taxa studied are present.

Keywords: Passifloraceae; Passiflora; Taxonomy; Subgenus Distephana; Brazil.

1 Professor Titular Sênior do Departamento de Botânica da Universidade Federal do Paraná e Bolsista Pesquisador do CNPq. Processo 302226/82-6 - accervi@ufpr.br

Endereço: Caixa Postal 19041, CEP 81531-990 - Curitiba, PR

2 Professor e Pesquisador das Faculdades Integradas Espírita de Curitiba. 


\section{Introdução}

O estudo do gênero Passiflora L. da família Passifloraceae, sempre despertou o nosso interesse, dada a sugestiva estrutura de suas flores e, até certo ponto, a complexidade taxonômica da família, no que se refere aos Subgêneros, Secções e Séries. Da mesma forma, a sua dispersão no ambiente trópico e seu potencial econômico reforçaram a dedicação de anos de estudo cujos resultados vêm se somando no tempo.

A constatação inicial da inexistência de acurados estudos taxonômicos e fitogeográficos para o gênero Passiflora em determinadas regiões justificou estudo anterior das espécies para o Sul do Brasil (Cervi, 1981, Cervi; Bidá, 1983); CentroOeste (Cervi, 1986, 1998); Sudoeste (Cervi,1994a, 1994b, 1996) e o estudo do subgênero Passiflora para as regiões Sul, Sudeste e Centro-Oeste brasileiro (Cervi,1991).

A partir das primeiras revisões, outras tarefas foram se impondo com desdobramentos para estudos mais complexos e amplos, como este que se acrescenta referente ao subgênero Distephana (Juss.) Killip.

Assim, tomamos a decisão de reunir e rever a identificação das espécies de Passiflora, do subgênero Distephana (Juss.) Killip para o Brasil no sentido de prover a atualização e a consolidação da descrição e posição sistemática daquelas espécies, bem como prover o reconhecimento das áreas de sua distribuição e sua ecologia.

Importantes contribuições, dadas a conhecer desde o século XIX, devem ser preliminarmente destacadas, de vez que constituem a literatura essencial e propiciam importante orientação ao presente estudo. Trata-se das obras de reconhecida relevância De Candole (1828), Masters (1871-1872), Velloso (1831), Usteri (1911), Harms (1894, 1925, 1929), Killip (1924, 1938, 1960), Uribe Uribe (1955) Melchior (1964), Sacco (1962, 1966, 1968, 1973, 1980), Wilde (1974), Gentry (1981), Holm-Nilsen et al..(1988), Ulmer; Ulmer (1997).

Metodologicamente, vimos seguindo a mesma sistemática da construção teórica de nossos trabalhos anteriores:

1. Construção de uma chave indentada para determinar as espécies de Passiflora do subgênero Distephana.

2. Redescrição das espécies do gênero Passiflora, distribuição geográfica, observações ecológicas, fenologia e outras informações suplementares.

Além da revisão bibliográfica, consultamos, sempre que foi possível, as espécies-tipo e as coleções de espécies depositadas nos herbários nacionais e estrangeiros, aspirando maior segurança e objetividade do estudo encetado.

Um esforço especial foi dedicado ao presente trabalho, com a pretensão de compensar as limitações de recursos técnicos disponíveis para a sua realização, buscando, sobretudo, não comprometer sua utilidade e seriedade.

\section{Ma terial e Método}

O material utilizado na presente pesquisa inclui recursos bibliográficos, coleções exsicatadas e coletas de material vivo.

\section{Recursos bibliográficos}

O estudo taxonômico partiu, inicialmente, da revisão da literatura existente. Foram consultadas obras clássicas de Botânica Sistemática bem como trabalhos específicos e correlatos ao objeto sob análise, publicados e/ou divulgados em eventos científicos, pertencentes a acervos de bibliotecas nacionais e estrangeiras, públicas e particulares.

\section{Coleções ex sicata das}

A organização das informações e registros específicos impôs o conhecimento e análise das coleções exsicatadas da família Passifloraceae do subgênero Distephana e gênero Passiflora, depositadas nos principais herbários brasileiros, norte-americanos e europeus.

$\mathrm{O}$ acesso às coleções, deu-se, na maioria dos casos, mediante visitas aos herbários. Todavia, ressaltamos a colaboração muito especial de instituições que liberaram precioso material sob forma de empréstimos.

O material exsicatado foi analisado através de empréstimo ou de consultas nos próprios herbários. As siglas estão de acordo com Mori et al. (1989) e Holmgren et al. (1990). São os seguintes herbários: 
BHCH Herbário do Departamento de Botânica Universidade Federal de Minas Gerais Belo Horizonte - MG

BM Herbarium British Museum. Londres.

BR Herbarium Nationale Plantentuin van België - Meise - Belgium

$\mathrm{CH}$ Universidade Federal do Mato Grosso Cuiabá -MT

CEN Herbário do Centro Nacional de Recursos Genéticos (EMBRAPA) Brasília - DF.

G Herbarium Conservatoire et Jardin Botaniques de la Ville de Genève -Suíça.

HB Herbarium Bradeanum - Rio de Janeiro - RJ.

ICN Universidade Federal do Rio Grande do Sul - Porto Alegre - RS.

INPA Instituto Nacional de Pesquisas da Amazônia - Manaus - AM.

IAN Centro de Pesquisa Agropecuária do Trópico Úmido - EMBRAPA - Belém -PA

JPB Universidade Federal da Paraíba. Herbário Lauro Pires Xavier. João Pessoa - PB

K The Herbarium, Royal Botanic Garden, Kew, England

M Herbarium Botanische Staatssammlung München - Alemanha.

MBML Museu de Biologia Mello Leitão - Santa Tereza, ES.

MBM Museu Botânico Municipal - Curitiba - PR

NY The New York Botanical Garden - New York, U.S.A.

P Museum National D'Histoire Naturelle Paris - França.

PACA Colégio Anchieta - Instituto Anchieta e UNISINOS - São Leopoldo - RS

R Museu Nacional do Rio de Janeiro - RJ

RB Jardim Botânico do Rio de Janeiro - RJ

ULM Herbarium der Universität Ulm. - Ulm Germany

UPCB Universidade Federal do Paraná - Curitiba - PR

US United States National Herbarium Smithsonian Institution - Washington, U.S.A.

\section{Métodos}

O material herborizado foi submetido ao seguinte tratamento:

a) Reidratação das unidades florais, através de fervura em água durante 3 a 4 minutos. b) Análise do material hidratado através de microscópio estereoscópico binocular, modelo Mycronal e Carl Zeiss, com vários aumentos.

c) Utilização de régua milimetrada para a conferência de medidas.

d) Representação gráfica do material estudado: os desenhos foram realizados diretamente da observação do material exsicatado utilizando quando necessário o microscópio estereoscópico, com os aumentos necessários para os referidos desenhos.

Para a identificação das espécies foram utilizadas chaves analíticas de Killip (1938), Sacco (1980), Escobar (1988) e Cervi (1981, 1991)

A confirmação das espécies efetuou-se por comparação com a descrição original, com descrições posteriores, além da utilização dos Holótipos, Isótipos e Parátipos. Utilizou-se também desenhos e estampas, bem como fotografias e Fotótipos de material exsicatado referenciado na literatura.

Na descrição morfológica, os valores das medidas são separados por um "x", que correspondem ao comprimento e largura respectivamente.

O ponto de exclamação colocado junto ao acrônimo do herbánio indica que o material tipo foi visto e examinado.

As abreviações dos autores das espécies estão de acordo com Brummit e Powell (1992).

Sinopse do Subgênero Distephana (Juss.) Killip, Publ. Field. Mus. Nat. Hist., Bot. Ser. 19(1):29.1938. 6:396.1805

Distephana Juss. in Ann. Mus. Hist, Nat.

Tacsonia sect. Distephana (Juss.)DC. Prodr. 3:335.1828.

Macrophora Raf. Fl. Tellur 4:103.1838.

Passiflora subgênero Tacsonia sect. Distephana (Juss.) Triana \& Planch. Ann. Sci. Nat. V Bot. 17:127.1873.

Passiflora sect. Distephana (Juss.) Harms in Engl. \& Prantl. Pflanzenfam. 21:504.1925.

Trepadeira com gavinhas axilares, caule com crescimento secundário anômalo. Folhas simples e inteiras ou trilobadas, ocasionalmente pode apresentar mais de três lóbulos. Pecíolos com glândulas; estípulas setáceas a linear lanceoladas. Pedúnculos robustos com uma única flor ereta; 
brácteas foliáceas ou setáceas, com glândulas nas margens. Flores vermelhas ou rosadas.Tubo do cálice de $0,4-1,8 \mathrm{~cm}$ de comprimento por 1,0 $1,2 \mathrm{~cm}$ de diâmetro; sépalas, geralmente com glândulas nas margens; corona de filamentos com duas a quatro séries, sendo uma ou duas séries filamentosas, e uma série tubular, membranosa, fimbriada no ápice; opérculo ereto, fimbriado na margem; ovário truncado no ápice. Frutos obovados, ovalados ou globosos de pericarpo frágil e quebradiço, ao madurar com filas e pontosalvos; sementes com testa reticulada de coloração marrom; arilo branco ou amarelado, suculento.

Espécie-tipo: Passiflora glandulosa Cav.

\section{Chave para as espécies brasileiras de Passiflora do subgênero Distephana}

1. Folhas simples e inteiras.

2. Folha coriácea ou subcoriácea de margem inteira.

3. A série de filamentos externa constituída por uma membrana tubular de margem filamentosa. P. variolata 3. A série de filamentos externa constituída por filamentos livres na base.............................................. glandulosa

2. Folhas membranáceas de margem denteada

4. Corona de filamentos em 2 ou 3 séries, corona divergente do androginóforo, fru tos ovalados ou globosos

5. Corona de filamentos em 2 séri es, frutos globosos. ..P. tholozanii

5. Corona de filamentos em 3 séries, frutos ovóides ou subglobosos

6. A série de filamentos internos unidos na base .............P. coccinea

6. A série de filamentos inter nos livres na base................P. araujoi
4. Corona de filamentos em 4 séries, corona convergente ao androginóforo, fru tos piniformes. .P.quadrifaria

1. Folhas inteiras e trilobadas

7. Corona de filamentos em 2 séries P. speciosa

7.Corona de filamentos em 3 séries.

8. Brácteas de 3 a $7 \mathrm{~cm}$ de comprimento P. involucrata

8. Brácteas de 0,8 a 2,5 cm de comprimento

9. A série interna de $1,0 \mathrm{~cm}$ de comp. constituída por uma mem brana tubular circundando 0 androginóforo .................. vitifolia 9. A série interna de $1,5 \mathrm{~cm}$ de comp. constituída por uma mem brana tubular $(1 / 3)$ e margem filamentosa(2/3).............P. quadriglandulosa

\section{Resultados}

Passiflora araujoi Sacco in Ann. XV Congr. Soc. Bot. do Brasil 1:153, fig.2. 1967.

Tipo: Brasil: Pará, Marituba, Granja Imperial, Leg. E. Pereira 5037, 30/VIII/ 1959 (Holótipo HB!).

Planta trepadeira com caule cilíndrico, estriado, ferrugíneo tomentoso. Estípulas lineares de $0,7-1,5 \mathrm{~cm}$ compr., com glândulas na margem. Pecíolos ferrugíneo-tomentosos de 1 2,5cm compr., com 2 - 4 glândulas sésseis. Folhas simples, inteiras, de margem duplo-serrada, ovalelípticas, de ápice acuminado e base atenuada a subcordada, membranáceas, ferrugíneo-tomentosas na face abaxial e lustrosas na face adaxial de 5-14 x 3-6cm. Pedúnculos robustos articulados acima do ponto de inserção das brácteas, de $4-7,5 \mathrm{~cm}$ compr. Brácteas de 2,5-4,7 x 0,8-1,4cm, involucradas, foliáceas, oval-elípticas, ferrugíneotomentosas de base cuneada e ápice agudo e margem glandular-serrulado, inseridas $0,5 \mathrm{~cm}$ abaixo da base da flor. Tubo do cálice cilíndrico campanulado, sulcado de 0,8-1 cm compr. Sépalas 
oblongas de 2,6-4 x 0,8-1 $\mathrm{cm}$, carinada, a quilha termina em uma arista de $0,3-0,4 \mathrm{~cm}$ de compr. Pétalas oblongas de 2,2-3 x 0,8-1 $1 \mathrm{~cm}$. Corona de filamentos em 3 séries, as 2 séries externas formadas de filamentos subulados de 0,7-1,2cm de compr.; a série interna formada de filamentos filiformes de 0,3-0,7cm compr., livres desde a base. Opérculo recurvado e de margem fimbriada. Limen anular. Ovário ovóide, amarelo-esverdeado, vilosotomentoso. Fruto ovóide, pubérulo. Sementes obovadas de 5-6 x 4-4,5 mm levemente reticulada. Icon.: Fig. 1.

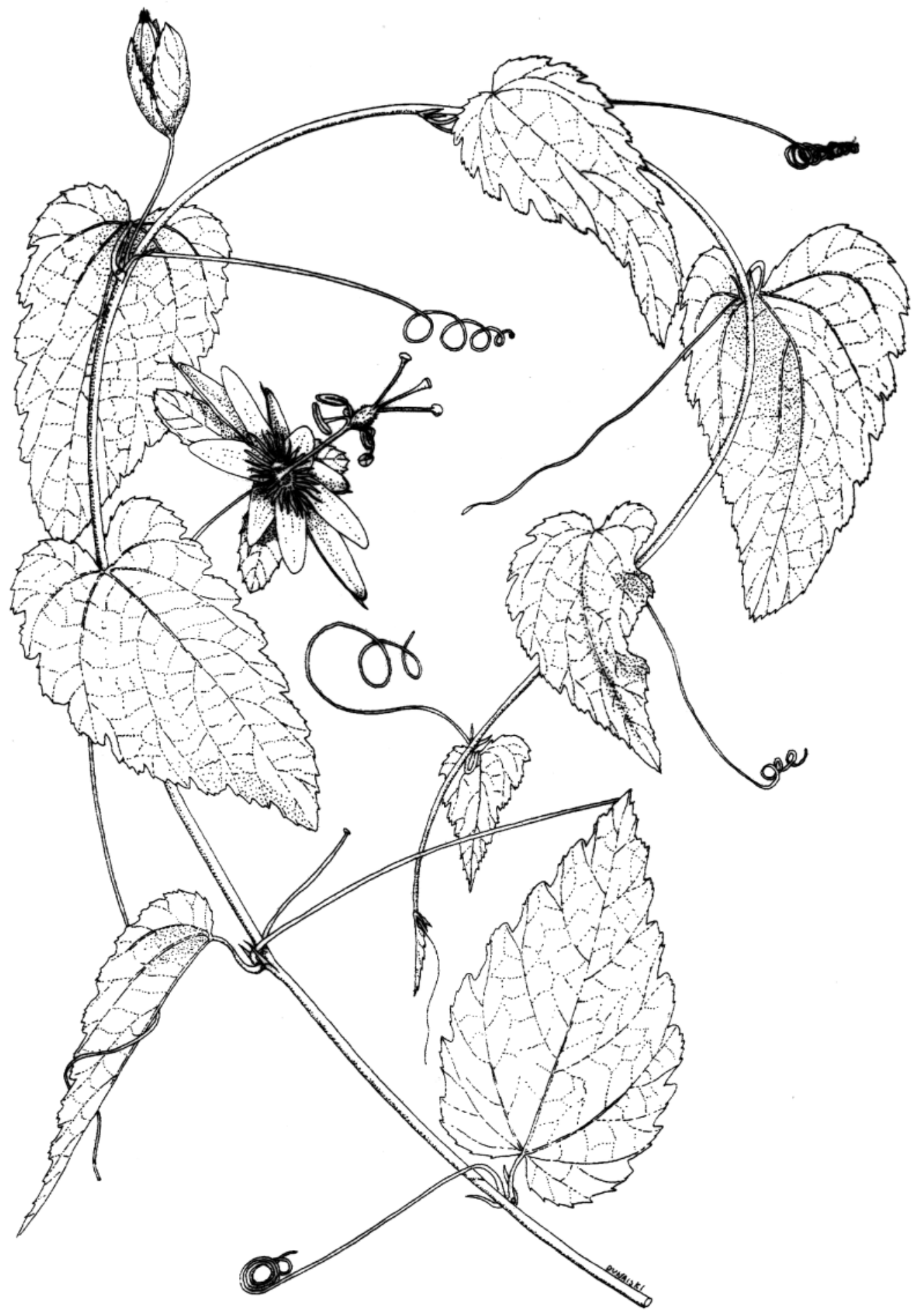

Figura 1. Passiflora araujoi Sacco: Hábito.Leg. A. Souza 1382 etal. 18/7/85. Ma to Grosso. Pontes e Lacerda, Chapada dos Parecis ( $R$, UPCB) 
Material examinado: Brasil: Amazonas: Tefé, Leg. N.T.Silva 4407, 10/9/1976 (UPCB). Pará: Marituba, Granja Imperial, Leg. E. Pereira 5037, 30/ 8/59 (HB, Holótipo); Belém, Instituto Agronômico do Norte, Leg. E. Pereira 3307,16/10/57 (HB, Parátipo; RB, Paratipo); Belém, Leg. J.M. Pires \& A. Black 479, 22/10/45 (IAN, Parátipo) Óbitos, Leg. A. Ducke, s/n, 88/11/1119 (RB, Parátipo); Óbitos, Leg. J.B. Rodrigues, s/n, 20/11/1872 (R, Parátipo); Belém, Leg. R. L Fróes 19907, IX/42 (US); Cachoeira do Tronco, Leg. A.J. Sampaio 5000,16/9/29 (R, Parátipo); Roraima: Ouro Preto do Oeste, Parque Nacional Pacoas Novos, Leg. J. Augusto 1815 et al., 13/7/86 (R, UPCB); Vilhena, Leg. J. Augusto 1877, 18/7/86 (R, UPCB); Vilhena, km 39, rumo a Cacoal, Leg. L. A, Skorupa 608 et al. s/d (CEN, UPCB); Rondônia: Santa Barbara, Leg. G.T. Prance \& J. F. Ramos 6923 14/8/68 (INPA, NY, US, K); Jaciparaná, Leg. G.T. Prance 5174 et al., 24/6/68 (INPA, NY, US, K, P); Maranhão: Rodovia BelémBrasília, Leg. E. Oliveira 1039, 24/8/60 (IAN, Parátipo). Mato Grosso: Sumidouro, Rodovia Sumidouro-Diamantino, km 25, Leg. L Coradin 7021 et al., 27/8/84 (CEN, UPCB); Vila Bela da Santíssima Trindade, Leg. M. Emmerich 5790 et al., 27/7/86 (R, UPCB); Idem, A. Souza 1337 et al., 14/ 7/85 (R, UPCB); Pontes e Lacerda, Chapada dos Parecis, Leg. A. Souza 1382 et al., 18/7/85 (R, UPCB); Chapada dos Parecis, Uirapuru, Leg. M. Emmerich 6000 et al., 26/7/86 (R, UPCB); Posto Galera, BR 174, Leg. M. Emmerich 5790, s/d (R, UPCB); Barão de Capanema, Leg. F.C. Hoehne 2099, 6/1/09 (R, Parátipo); Juruena, Leg. F.C. Hoehne 1973, 5/1/09 (R, Parátipo); Rio Xingu, Leg. H. Sick B351, 9/1/47 (RB, Parátipo); Rio Arinos, Cachoeira do Pau, Leg. A. Schultz 1501, 26/6/57 (ICN, Parátipo).

Distribuição geográfica: Brasil: Amazonas, Pará, Roraima, Rondônia, Maranhão e Mato Grosso.

Dados fenológicos: Floresce de julho a novembro e frutifica de novembro a fevereiro.

Observações ecológicas: Espécie heliófita que se desenvolve na orla de floresta e principalmente em capoeiras e capoeirões.

Etimologia: Esta espécie foi descrita em homenagem ao Prof. José Emílio Gonçalves de Araújo, Assessor Técnico do Instituto de Pesquisas e Experimentação Agropecuárias do Sul e Catedrático de Geologia Agrícola da Escola de Agronomia Elizeu Maciel de Pelotas - Rio Grande do Sul.

Observação: A espécie mais próxima de Passiflora araujoi é Passiflora coccinea, da qual pode ser distinguida pela corona de filamentos. Em Passiflora araujoi os filamentos da corona são livres desde a base e em Passiflora coccinea a série interna de filamentos é unida na base por uma membrana.

Passiflora coccinea Aubl. Pl. Guian. 2: 828. pl. 324. 1775.

Passiflora velutina DC. Prodr. 3: 327. 1828. Tacsonia pubescens DC. Prodr. 3: 335.

1828

Passiflora fulgens Wallis ex Morren, Bel Hort. 16: 193. pl. 13. 1866.

Passiflora coccinea var. minor Mast. in Mart. Fl. Bras. 13, pt.1:605. 1872.

Passiflora coccinea var. velutina Mast. In Mart. Fl. Bras. 13, pt. 1: 605. 1872.

Passiflora toxicaria Barb. Rodr. in Contr. Jard. Bot. RJ. 4: 94. pt. 17aㅡ 1907.

Tipo: Guiana Francesa: Oyac (P, Holótipo no herbário histórico de Jussieu (P!); Fotótipo (P!)

Planta trepadeira com caule cilíndrico ou subangular, levemente pubescente ou densamente tomentoso. Estípulas lineares ou linear-setáceas de $4-6 \mathrm{~mm}$ compr. com as margens gladularserreadas. Pecíolos de 3-3,5cm compr. com duas glândulas na base da lâmina foliar. Folhas simples, inteiras, membranáceas, oblongas ou mais raramente orbiculares de $6-14 \times 3-7 \mathrm{~cm}$, ápice agudo, acuminado ou obtuso, subcordada na base; margem duplamente serreada ou mais raramente crenada; na face adaxial glabra, na face abaxial ferruginosa ou tomentosa. Pedúnculos solitários, robustos de até $8 \mathrm{~cm}$ compr. Brácteas ovaladas de 6 x 3,5cm, côncavas, livres na base, margem crenada ou serrada com glândulas, pubescentes ou tomentosas em ambas as superfícies. Tubo do cálice cilíndrico-campanulado de 1,5-2 x 1-1,3cm, na fauce. Sépalas linear-lanceoladas de 3-5 x 0,8$1 \mathrm{~cm}$, escarlates ou vermelhas, cuculadas, ligeiramente carinadas, a quilha termina em uma arista 
foliácea de 1,3cm compr. Pétalas lineares de 3,5-4 x $0,7-0,8 \mathrm{~cm}$, escarlates ou vermelhas. Corona de filamentos em 3 séries; as duas séries exteriores de filamentos subulados de $1 \mathrm{~cm}$ compr., bandeados de púrpura e branco; a série interior, unidas na base por uma membrana e a parte livre formada de filamentos de 6-8mm compr. Opérculo alvo, membranáceo, recurvado e filamentoso na parte superior, filamentos de $2 \mathrm{~mm}$ compr. Limem cupuliforme. Ovário ovóide, densamente tomentoso com tricomas amarelados. Fruto ovóide ou subgloboso de $5 \mathrm{~cm}$ de diâmetro, levemente tomentoso, com exocarpo quebradiço, alaranjado ou amarelo. Sementres obovadas de 6 x 4mm levemente reticulada. Icon.: Fig. 2.

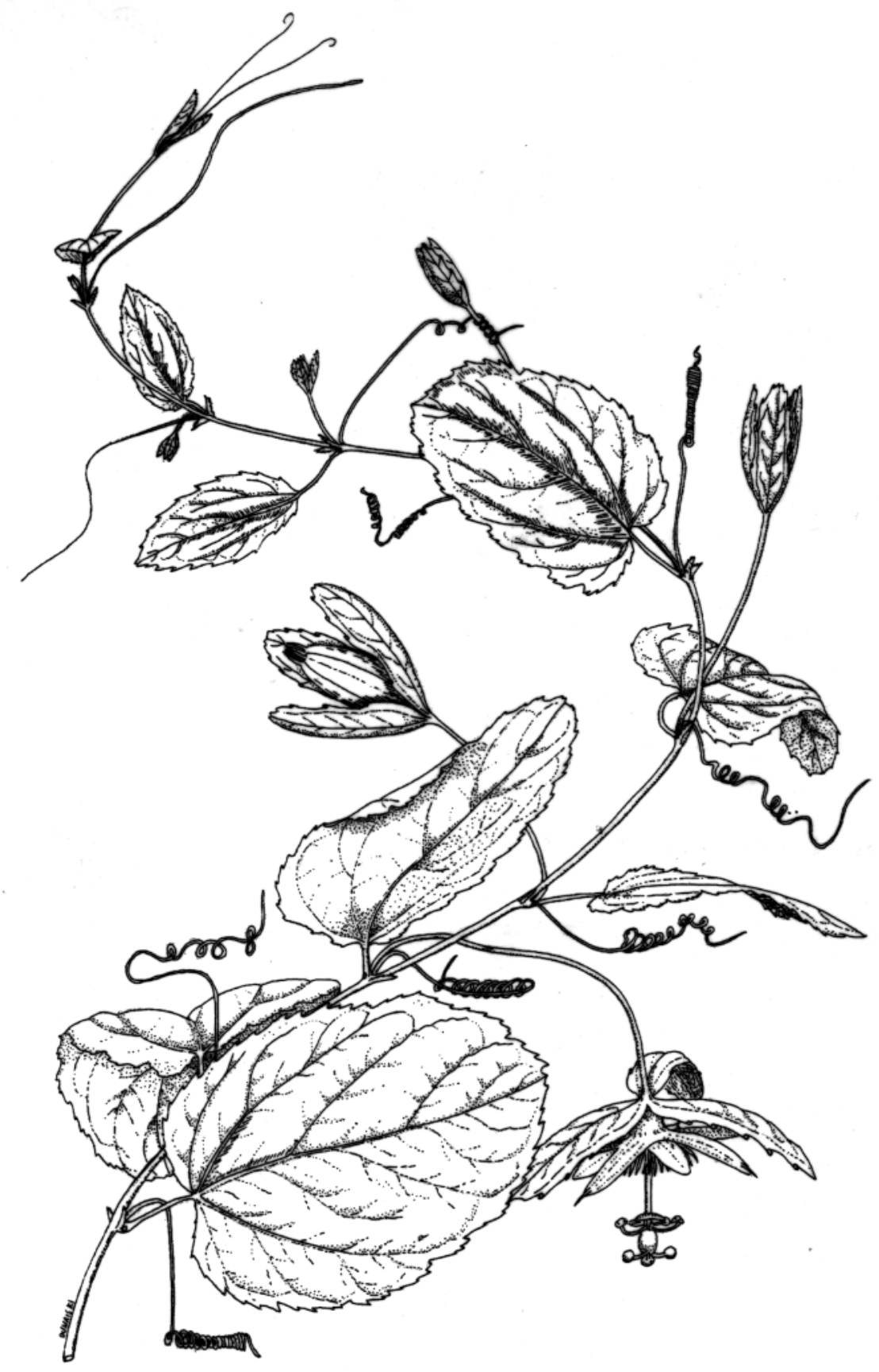

Figura 2. Passiflora coccinea Aubl.: Hábito. Leg. G. Hatschbach 63810 et al. 23/10/ 95. Mato Grosso. Barra dos Bugres (MBM). 
Material examinado: Brasil: Amazonas: Manaus, Estrada do Aleixo, Leg. L Xavier, s/ n, 7/2/40 (JPB); Manaus, Leg. M. Lobrog in 1906 (P), Manaus, São Raimundo, Leg. Ph.v. Luetzelburg 21983, 28/8/17 (M), Manaus, Reserva Ducke, Leg. M. A. S. Costa 694, 12/1/96 (K, UPCB); Manaus, Leg. P. Kukle \& B. Boom 58, 14/11/89 (MBM, NY, US); São Gabriel da Cachoeira, Cucui, Leg. C. Farney 1833 et al., 30/10/87 (UPCB, RB, NY); São Gabriel do Rio Negro, Leg.E.G. Holt \& E.R. Blake 601, XII/30 (P,US); Barra, Leg. Spruce 1709, VIII/ 1851 (P, K), Humaitá a Labrea, Leg. G.T. Prance 3458 et al., 29/9/66 (R, K, US); Humaitá, Leg. L O. A. Teixeira 1375 et al., 25/6/82 (NY), Humaitá, Leg. M.L Gasparini 13, 23/6/83(G); Humaitá, Leg. A. Janssen 500, 19/6/80 (M). Rio Solimões, Leg. Spruce 1637, VI/1851 (M); Rio Demeni, Leg. G.T.Prance 10248 et al., 26/2/69 (US, INPA, NY, P); Pará: Leg. C.F. Backer 67 in 1908 (G, BM); Leg. Martius 2627, s/d (M); Belém, Leg. E.P. Killip \& A.C. Smith 30247, 27/10 à 7/11/29 (P, US) Belém, Ilha do Mosqueiro, Leg. E.P. Killip \& A. C. Smith 30414, 3-9/11/29 (US) Belém R.L Froes 19907, IX/42 (K). Santarém, Leg. Jobert in 1877-78 (P), São João, Leg. A. P. Duarte 1817, 16/11/45 (R) ; Óbitos, Leg. A. Ducke 14637, 8/11/19 (RB, US); Jari, Estação Ecologica do Jari, Leg. H.T. Beck 107 et al., 14/10/87 (NY, US, INPA); Tucuruí, Leg. T. Plowman 9765 et al., 19/3/80 (NY); Abaeté, Leg. B. A. Kukroff 5864, 24/8/34 (K), Tomé Assu, Leg. Y. Mexia 6057a, 6/8/31 (K, US); Rio Aripecuru, Leg. Spruce 552, XII/ 1849 (K, Holótipo e Isótipo de P. cocinea var. minor Mast.); Estação Ecológica do Jari, Leg. H.T. Beck 107 et al., 14/10/ 87 (NY, UPCB); Ilha do Marajó, Salvaterra, Leg. J.P. Lemos Filho s/n, 15/8/97 (BHCB, UPCB).Serra dos Carajás, Leg. S.M. Silva 1337 et 1342, 3/7/86 (MBM); Acre: Rio Branco, Leg. L Emydio 1842, 29/8/60 (R); Rio Branco, Penalzinha, Leg. L. Emydio 1865, 9/9/60 (R); Rio Maconhan, Leg. B.A. Kukroff 5363, 8/8/33 (G); Amapá: Macapá, Leg. J. Mattos \& N. Mattos 10186, 18/3/92 (UPCB); Rio Oiapoque, Leg. H.S. Irwin et LY.Th. Westra 47252, 30/7/60 (US, NY); Serra do Navio, Rio Amapari, Leg. R. S. Cowan 38464, 20/11/54 (US). Rondônia: Maracá, Leg. W. Willeken \& L.F. Coelho 5520. 2/3/87 (K); Cerejeiras, Parque Estadual de Corumbiara, Leg. R.M. Britez s/n, 25/9/95 (UPCB); Rio Madeira, Leg. G.T. Prance 5958 et al., 13/7/68 (K, UPCB, US); Rio Madeira Mamoré, Leg. G.T. Prance 5571 et al., 4/ 7/68 (K, R, US). Rio Madeira, Japaraná, Leg. G.T. Prance 5174 et al., 24/6/68 (R). Mato Grosso: Leg.
M.H. Alg. Weddell 3404 et 3395, VII a VIII/1845 (P); Leg. S. More 312, s/d, (BM); Porto dos Gaúchos, Leg. W. Thomas 3987 et al., 23/9/85 (US); Alta Floresta, Salto do Rio Apiacás, Leg. C. A. C. Ferreira 6277 et al., 29/9/85 (INPA, NY, US); Cárcere, Posto Sape, Leg. P. C. Hutchison 8597 et al., 8/ 10/ 83 (US) Jurisena, Leg. Hoehne 1966, V/09 (R); Rio Barbado, Cavalvano Velho, Leg. G. Hatschbach 65612 et al., 16/11/96 (MBM); Corrêgo da Cascata, Leg. G. Hatschbach 66986 et al., 18/8/97 (MBM); Alto Paraguai, Estrada para Barra dos Bugres, km 51, Leg. C.N. Cunha 1303 et al., 5/8/83 (CH); Pontes e Lacerda, Leg. N. Saddi 3498, 24/10/83 (CH); Pontes e Lacerda, Leg. A. Souza 1346, 15/7/85 (R, UPCB); Pontes e Lacerda, km 9, Leg. G. Hatschbach 66924 et al., 16/8/97 (MBM); Pontes e Lacerda, Cataco, Leg. G. Hatschbach 65450 et al., 9/11/96 (MBM);; Rio Branco, Leg. G. Hatschbach 62640 et al., 11/5/95 (MBM); Marcelândia, Leg. N. Saddi 8338, 22/11/87 (CH), Rio Branco, Fazenda Saramandaia, Cachoeira do Cícero, Leg. N. Saddi 8862, 13/12/87 (CH); Barra dos Bugres, Leg. L.A. Skorupa 578 et 582 et al., 18/7/88 (CEN, UPCB); Vila Bela da Santíssima Trindade, Leg. M. Emmerich 5778 et al., 19/7/86 (R, UPCB); Aripuanã, Leg. G.T. Prance 18227 et al., 8/10/73 (NY, K, G, P, UPCB).Barra dos Bugres, Rod. MT-246, Leg. G. Hatschbach 63810 et al., 23/10/95 (MBM).

Distribuição geográfica: Brasil: Amazonas, Pará, Acre, Amapá, Rondônia e Mato Grosso.

Dados fenológicos: Floresce de julho a dezembro e frutifica de dezembro a março.

Observações ecológicas: Espécie heliófita que se desenvolve em capoeiras e capoeirões, às vezes tornando-se invasora na agricultura.

Etimologia: Do Latim: coccinatus, a, um = vestido de escarlate. Por apresentar as suas flores de cor vermelha ou escarlate.

Observação: Esta espécie é muito apreciada pelos seus frutos. Na Guiana e Martinica encontram-se os frutos a venda em feiras e mercados (Vanderplank, 1996a). Dado a facilidade de cultivo desta espécie, sugerimos, aos órgãos competentes, que se "domestifique" esta espécie e introduza-se no mercado para o consumo humano. 
Passiflora coccinea é semelhante à Passiflora araujoi e Passiflora tholozanii, porém, pode-se distingui-las pela estrutura da corona de filamentos, pois estas apresentam os filamentos livres desde a base e aquela a série interna de filamentos é unida na base.

Passiflora glandulosa Cav. in Diss, 10: 453. pl. 281. 1790.

Tacsonia glandulosa Juss. Ann. Mus. Hist. Nat. 6: 391. 1805.

Tacsonia caniculata Juss. Ann. Mus. Hist. Nat. 6: 392. 1805.

Tacsonia glandulosa var. caniculata DC.

Prodr. 3: 335. 1828. 1828.

Tacsonia Rohriana Dc. Prodr. 3: 335.

(?)Tacsonia Stoupyana DC. Prodr. 3: 335.

1828.

Tacsonia Fockeana Miq. Linnaea 18: 364.

1844

Distephana glandulosa M. Roemer, Fam. Nat. Syn. 2: 198. 1846.

Distephana glandulosa var. caniculata M.

Roemer, Fam. Nat. Syn. 2: 198. 1846.

(?)Distephana Stoupyana M. Roemer, Fam.

Nat. Syn. 2: 199. 1846.

Distephana Rohriana M. Roemer, Fam. Nat. Syn. 2: 199. 1846.

Distephana Fockeana M. Roemer, Fam. Nat. Syn. 2: 199. 1846.

62. 1848

Tacsonia subcoriacea Garcke, Linnaea 22:

(?) Passiflora glandulosa var. Stoupyana Mast. In Mart. Fl. Bras.13, pt. 1: 600. 1872.

Passiflora glandulosa var caniculata Mast. In Mart. Fl. Bras. 13, pt. 1:600. 1872.
Passiflora Thurnii Mast. Gard. Chron. III. 23: 305, 307. F.114. 1898.

Passiflora silvicola Barb. Rodr. Contr. Jard. Bot. RJ. 4: 91. pl. 14. 1907.

Tipo: Guiana Francesa: Cayena, Leg. Stoupy in 1788 (P, Holótipo!).

Planta trepadeira, caule cilíndrico ou subanguloso, glabro. Estípulas linear-subuladas ou setáceas, decíduas. Pecíolo até 2,5cm compr. com 2 glândulas sésseis no terço inferior do pecíolo. Folhas simples, inteiras, ovalado-oblongas ou oblonga-lanceoladas de $6-15 \times 4-10 \mathrm{~cm}$ agudas ou acuminadas, margem inteira ou ligeiramente ondulada; cordada ou arredondada na base, coriáceas a subcoriáceas, glabras em ambas as superfícies. Pedúnculo de 5-8cm compr. Brácteas de 5-10 x 1$2 \mathrm{~mm}$ larg., linear-lanceoladas com glândulas nas margens. Flores vermelhas ou escarlates. Tubo do cálice cilíndrico de 1,5-2,5 x 0,8-1cm. Sépalas oblongas ou linear-oblongas de 2-5 x 0,6-1,3cm com uma pequena arista próxima ao ápice. Pétalas do tamanho da sépala, vermelhas ou escarlates. Corona de filamentos em 2 séries; a série externa com filamentos em forma de sovela e de $1 \mathrm{~cm}$ compr., livres na base, alvos ou levemente róseos; a série interna formada na base por uma membrana e a parte livre filamentos lacerados de $2-5 \mathrm{~mm}$ compr. Opérculo a $3 \mathrm{~cm}$ de base do tubo, róseo, pendente e margem recurvada, ápice filamentoso. Limem membranáceo, cupuliforme, ereto envolvendo a base do androginóforo. Ovário elipsoidal, glabro ou às vezes puberulento. Fruto ovóide de 5-6 x 2,5-3cm de diâmetro, pericarpo coriáceo. Sementes obovadas de 8 x 4mm, levemente reticulada. Icon.: Fig. 3. 


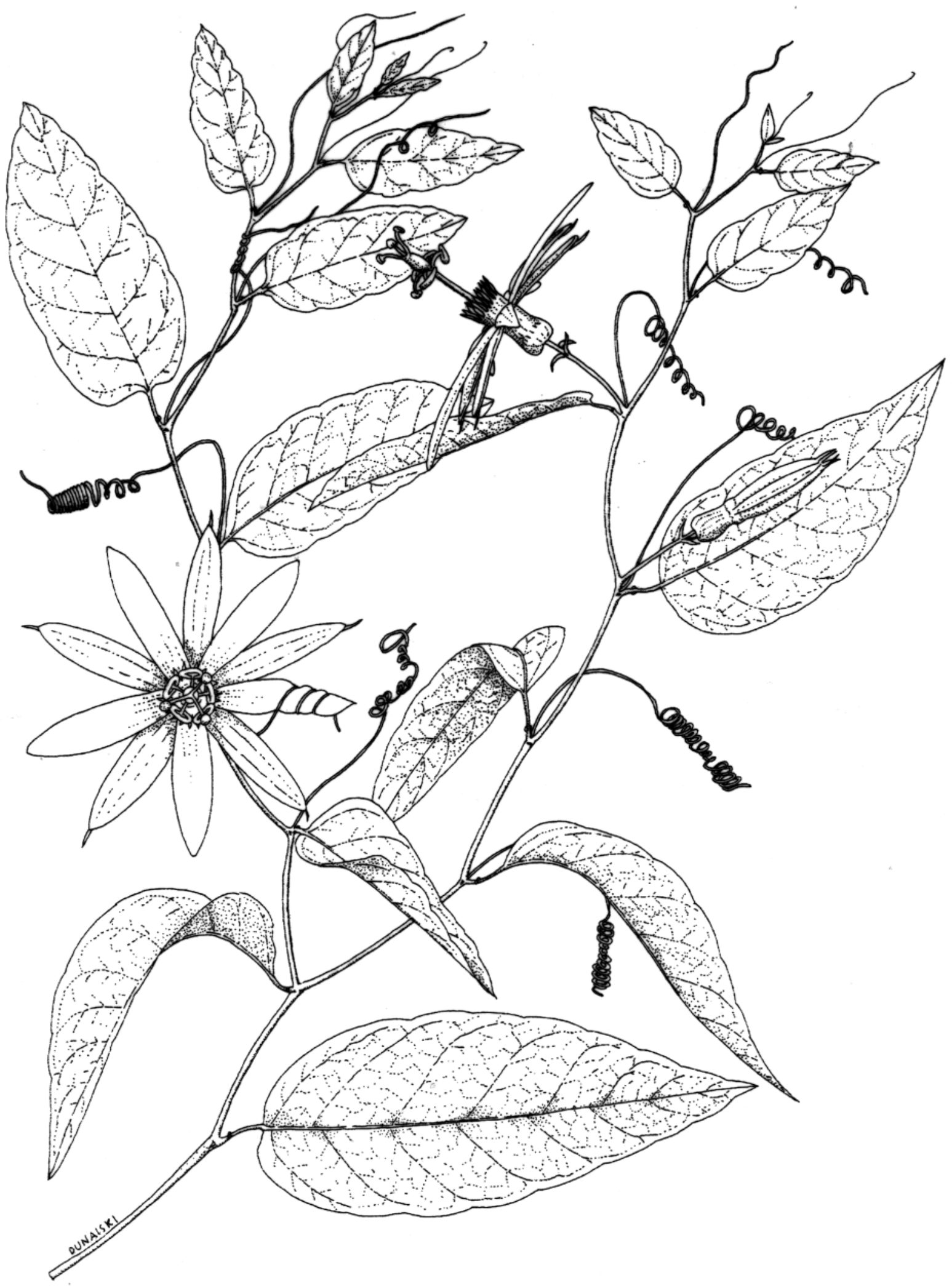

Figura 3. Passiflora glandulosa Cav.: Há bito. Leg. A. R. Marques s/n, 17/ 7/97. Pará. Ilha do Marajó. Salva terra (BHCB, UPCB). 
Material examinado: Brasil: Amazonas: Manaus, Reserva Ducke, Leg. J.E.L.S. Ribeiro 973 et al., 2/7/93 (K); Manaus, Leg. A. Ducke 23558, 11/7/29 (RB, US) Manaus, Comunidade Nossa Senhora de Fátima, Leg. LV. Ferreira 239, 16/5/92 (K); Rio Branco, Leg. J.G. Kuhlmann 3412, VIII/13 RB, US); Prainha, Leg. J.W.H. Traill 356, 17/2/1873 $(\mathrm{K})$, Rio Xingu, Gleba Bacaja, Leg. G.T. Prance P26477 et al., 26///11/80 (NY, UPCB); Pará: Altamira, Leg. J. R. Swallen 6899, X/43 (US); Belém, Leg. J. T. Baldwi Jr 4526, 17/6/44 (US); Belém, Ilha do Mosqueiro, Leg. E. P. Killip \& A.C. Smith 30500, 3/11/29 (US); Belém. Leg. E.P. Killip \& A.C. Smith 30294, X/XI/29 (US); Serra dos Carajás, Leg. J.P. Silva 51,15/8/87 (UPCB); Serra dos Carajás, Leg. C.R. Sperling 6218 et al., 17//6/82 (K, UPCB); Rio Tapajós, Leg. A. Ducke 648, 30/V/23 (RB, US); Ilha do Marajó, Leg. A. R. Marques s/n, 17/8/97 (BHCB, UPCB); Ilha do Marajó, Salvaterra, Fazenda Santa Rita, Leg. R.F.A.Veiga \& G.P.Silva 227, 28/10/87 (UPCB); Altamira, Itaituba, km 115, Leg. P. Bamps 5194, 19/1/76 (BR), Santarém, Leg. R. Spruce, s/n in 1849/50 (K); Santarém, leg. Jobert 256 et 855 in 1877/78 (P); Capanema para Maranhão, Leg. G.T. Prance \& T. D. Pennington 1709, 27/10/65 (K, US); Rio Muriapiranga, Leg. G.T. Prance, T. D. Pennington \& N. T. Silva 1601, 11/10/65 (US, NY); Rio Pacajá, Leg. G. T. Prance, T. D. Pennington \& N.T. Silva 1308, 16.9.65 (NY, US); Almeirim, Leg. M.J. Pires \& N. Silva 1846, 11/11/87 (K); Almeirim, Leg. M.J. Pires 622 et al., 17/9/85 (UPCB); Belém, Leg. L Macias, s/n, 9/1/84 (UPCB), Paragominas, Leg. T. Plowman 9395 et al. s/d (NY); Acre: Mâncio Lima a $20 \mathrm{~km}$ de Cruzeiro do Sul, Leg. M. Silveira 803 et al., 7/4/94 (NY); Amapá: Macapá, 15 km NW de Porto Grande, Leg. B. V. Rabelo, J. Cardoso \& A. Viana 3079, 24/12/84 (ULM); Oiapoque, Rio Urucuna, Tribo Polikur, Leg. B. V. Rabelo \& R. Nonato 1773,24/11/82 (ULM); Calçoene, Leg. B.V. Rabelo 2955 et al., 11/12/84 (UPCB, NY); Roraima: Boa Vista, Caracarai, Leg. G.T. Prance 9521 et al. 31/1/69 (R, K); Maranhão: Leg. D.M. Gorg 152 in 1852 (BR); São Luis, B. A. Kukroff 11540, II/III/ 1939 (K); São Luis, I \& G. Gottsberger 12-12981, 12/9/81 (ULM, UPCB) São Luis, Leg. R. Froes 11540, II/III/1939 (G, US); Santa Quitéria, Leg. B.A.S. Pereira 2529, 7/9/93 (IBGE, UPCB, US) Pinheiro Silva, Leg. D.N.S. s/n, II/1916 (R); Br 316 próximo a Peritó, Leg. M. A. Souza 1089 et al., 26/9/83 (JPB); Rosilândia, entre Pindaré-Mirim e Alto Tuń, Leg. S. Tavares 1083, 21/10/62 (US); Ceará: Guaraciaba do Norte, Chapada da Ibiapaba, Leg. A. Fernandes s/n, 27/12/79 (UPCB); Ubajara, Leg. Z. Trinta 1304 et al., 27/1/68 (PACA, R); Paraíba: Mamanguape, Caiana, leg. C.A. B. Miranda et al., s/n, s/d (JPB); João Pessoa, Restinga do Jacarapi, Leg. O.T. Moura 178, 20/3/84 (JPB, UPCB0); Pernambuco: Iguarassu, Leg. G. P. Ramage s/n, 19/11/1887 (BM); Rio de Janeiro: Quinta São Cristóvão, Leg. Glaziou 10874, 15/8/1877 (3 exsicatas, cultivadas) (K, P, R)

Distribuição geográfica: Brasil: Amazonas, Pará, Acre, Amapá, Roraima, Maranhão, Ceará, Paraíba e Rio de Janeiro (cultivada).

Dados fenológicos: Floresce de setembro a dezembro e frutifica de dezembro a março.

Observações ecológicas: É uma espécie heliófita com uma grande área de dispersão, vegetando na orla e clareira das florestas, em capoeiras e capoeirões. Quando no interior da floresta, desenvolve sua ramagem até encontrar luz no alto da copa das árvores.

Etimologia: Por apresentar um par de glândulas no pecíolo foliar.

Observação: Passiflora glandulosa é fácil de ser reconhecida, pois apresenta folhas simples, inteiras e lustrosas. Esta espécie assemelha-se com Passiflora variolata. Facilmente diferencia-se P. glandulosa de P. variolada pela corona de filamentos, sendo que esta apresenta na base da série externa de filamentos uma membrana tubular e aquela apresenta a sénie de filamentos livres desde a base.

Passiflora involucrata (Mast.) A.H. Gentry in Pl. Syst. Evol. 137: 101. 1981.

Passiflora vitifolia var involucrata Mast. in Mart. Fl. Bras. 13, pt. 1: 608. 1872.

Passflora punicea Mart. ex Mast. In Mart. Fl. Bras. 13, pt 1: 608. 1872.

Passiflora quadriglandulosa var. involucrata (Mast.) Killip, in Field Mus. Publ. Bot. Ser. 19: 319. 1938.

Tipo: Amazonas; Rio Japurá, Cataratas de Cubatã, Leg. Spruce 3022 (K, Holótipo!) 
Plantas trepadeiras, caule cilíndrico pubescente. Estípulas setáceas de 3-5mm compr. decíduas. Pecíolos de 3,8-6cm compr., com duas glândulas em forma de disco na base da lâmina foliar. Folhas simples, trilobadas, lóbulos de $10-16,9 \times 11-14,5 \mathrm{~cm}$. duplamente serreadas na margem, coriáceas, lustrosas na face adaxial e levemente pubescente na face abaxial. Pedúnculos de $8-8,5 \mathrm{~cm}$ compr. Brácteas obovadas, de 3-7 x 1,8-3,6cm, agudas a obtusas no ápice, cuneadas na base, duplamente glândular-serreadas nas margens, vermelhas. Inflorescência em racemo com 5-8 flores; flores de 7,3-7,6cm compr. Tubo do cálice, curtocilíndrico de 1,3-1,8 x 1-1,2cm. Sépalas oblongo-lanceoladas de 6-8,5 x 1-1,4cm com uma arista foliácea de 1,8cm comp. Pétalas de 4,7$7,5 \times 0,8-1,2 \mathrm{~cm}$, vermelhas. Corona de filamentos em 3 séries, as 2 séries externas filamentos de coloração vermelha ou escarlate brilhante; filamentos lineares na base e subulados na parte apical; a primeira série de $1,5 \mathrm{~cm}$ compr. a segunda série de $0,8-1,0 \mathrm{~cm}$ compr.; a série interior de $1,5 \mathrm{~cm}$ compr. constituída na base por uma membrana tubular (1/3) e margem filamentosa (2/3), filamentos de coloração alva. Opérculo de 6-7mm compr., pendente e margem recurvada e filamentosa. Ovário ovóide, tomentoso ferrugíneo. Fruto ovóide de $3,5 \mathrm{~cm}$ de compr. por $1,5 \mathrm{~cm}$ de diâmetro. Sementes ovaladas e reticuladas.

Material examinado: Amazonas: Rio Japurá, Cataratas de Cubatã, Leg. Spruce 3022 (K, Holótipo); São Paulo de Olivança, Leg. B.A. Krukoff 8925, 16/10 a 11/12/1936 (G, P, K, BR, $\mathrm{BM})$; Tefé, Paranaguá, Rio Juruá, Leg. B. A. Krukoff 4532, 22/8/33 (G); Pará: Rio São Manoel, Leg. J. M. Pires 3808, 5/1/ 72 (IAN); Rio Tapajós, Leg. A. Ducke 14644, 26/8/ 23 (K, IAN). Rio Solimões, Igarapé Jandiatuba, Leg. R.L. Fróes 24065, 2/2/49 (US).

Distribuição geográfica: Espécie restrita ao norte do Brasil: Amazonas e Pará.

Dados fenológicos: Floresce de agosto a dezembro e frutifica de dezembro a fevereiro.
Etimologia: Por apresentar as flores envoltas pelas brácteas, quando em botão.

Observação: Esta espécie pode ser confundida com Passiflora quadriglandulosa. Passiflora involucrata pode ser facilmente diferenciada de P. quadrigladulosa pelas brácteas obovadas e com a margem duplamente glândular-serreadas.

Passiflora quadrifaria Vanderplank in Curtis Bot. Mag. 13(2): 63-69. Fig. 1,2,3. 1996.

Tipo: Brasil: Amazonas, Jari, Estação do IBAMA. Cultivada no Royal Botanic Gardens, Kew, 26/5/95 (MG holótipo, K, Isótipo).

Planta trepadeira de caule cilíndrico levemente tomentoso. Estípulas lineares, setáceas de $3-5 \mathrm{~mm}$ compr. nos ramos jovens e 1,8-2,2. $\mathrm{x}$ $0,23 \mathrm{~cm}$ nos ramos velhos, com glândulas sésseis nas margens, Pecíolos robustos de 1,5-6cm compr.com duas glândulas sésseis de $2,5 \mathrm{~mm}$ de diâmetro na base da lâmina foliar. Folhas simples, inteiras, ovadas ou oblongas de 14,5-22 x $6-13,5 \mathrm{~cm}$, três nervuras na base, margem duplamente glandular-serradas. Pedúnculos de 7$8 \mathrm{~cm}$ compr. robustos e tomentosos. Brácteas de 6-7 x 3,5-4,5 cm., ovaladas, côncavas e livres na base, levemente tomentosas e margens com glândulas auriculadas de 0,5-1,5mm de diâmetro. Flores vistosas vermelhas ou escarlates. Tubo do cálice campanulado de $2-2,1 \mathrm{~cm}$ de diâmetro. Sépalas 4,5-5 x 1,4-1,6cm, lanceolada e com uma arista foliácea na parte abaxial de 0,9-1,2cm compr. Pétalas 4,2-4,5 x 1,1-1,2cm, oblonga e de ápice obtuso. Corona de filamentos em 4 séries, vermelhas, envolvendo 0 androginóforo, somente a série externa visível quando a flor esta aberta; a série externa com $1,4 \mathrm{~cm}$ compr., livre desde a base; a $2^{\mathrm{a}}$. série com $1,2 \mathrm{~cm}$ de compr.; a $3^{\underline{a}}$ e $4^{\mathrm{a}}$ séries com 0,8cm compr. Opérculo 1,2-1,4 cm compr., vermelho, pendente, encurvado e no ápice filamentoso, filamentos de 4-5mm comp. Ovário de $5 \times 3,5 \mathrm{~mm}$ levemente tomentoso, piriforme. Fruto de 3,3-3,8 x 2,3-2,6cm de diâmetro, piriforme, exocarpo levemente tomentoso, aromático. Semente de 5,5-6 x 2,5$3 \mathrm{~mm}$, ovalada assimétrica, reticulada. (Apud VANDERPLANK, 1996a,b). 
Observação: Deixamos de retratar os dados fenológicos, observações ecológicas e etimologia por não termos tido a possibilidade de examinar o material citado na obra "princeps".

Distribuição geográfica: Amazonas. Passiflora quadriglandulosa Rodschied in Med. Chir. Bemerek Esseq. 77. 1796.

Tacsonia quadriglandulosa (Rodschied) DC. Prodr. 3: 335. 1828.

Passiflora translinearis Rusby, Mem NY. Bot. gard. 7: 309. 1927 (somente a flor).

Passiflora yacumensis Rusby, Mem NY. Bot. Gard. 7:310. 1927.

Tipo: Guiana: Delta do Rio Essequibo, Leg. Jenman 6362 (BRG, Holótipo)

Plantas trepadeiras, caule cilíndrico glabro. Estípulas setáceas de 3-5mm compr. decíduas. Pecíolos de 1-2,5cm compr., obscuramente biglândular base da lâmina foliar. Folhas simples, trilobadas, polimórficas, oblongas a oblongo-lanceoladas de $8-15 \times 3-8 \mathrm{~cm}$ ou lobadas assimétricas com 2 ou 3 lóbulos (lóbulos acuminados, o mediano ovado- lanceolado de tamanho igual aos laterais), arredondadas ou subtruncadas na base e margem irregularmente denteada, glabra na face adaxial e puberulenta ou tomentosa na face abaxial.. Pedúnculos de 5-5,5cm compr. Brácteas lineares a oblongo-lanceoladas de 0,8-1,5 x 1-5mm com as margens glandular-serreadas. Flores visto sas, róseas, vermelhas ou escarlates. Tubo do cálice, curto-cilíndrico de 1,3-1,8 x 1-1,2cm. Sépalas oblongo- lanceoladas de 6-8,5 x 1$1,4 \mathrm{~cm}$. com uma arista foliácea de $1,8 \mathrm{~cm}$ compr. Pétalas de 6-7 x 0,8-1cm, vermelhas. Corona de filamentos em 3 séries, as 2 séries externas filamentos de coloração vermelha ou escarlate brilhante; filamentos lineares na base e subulados na parte apical; a primeira série de $1,5 \mathrm{~cm}$ compr. a segunda série de $0,8-1,0 \mathrm{~cm}$ compr.; a série interior de $1,5 \mathrm{~cm}$ compr. constituída na base por uma membrana tubular (1/3) e margem filamentosa (2/3), filamento de coloração alva. Opérculo de $6-7 \mathrm{~mm}$ compr., pendente e margem recurvada e filamentosa. Ovário ovóide, tomentoso ferrugíneo. Fruto ovóide de 3,5 x 1,5cm de diâmetro. Sementes ovaladas reticuladas. Icon.: Fig. 4. 


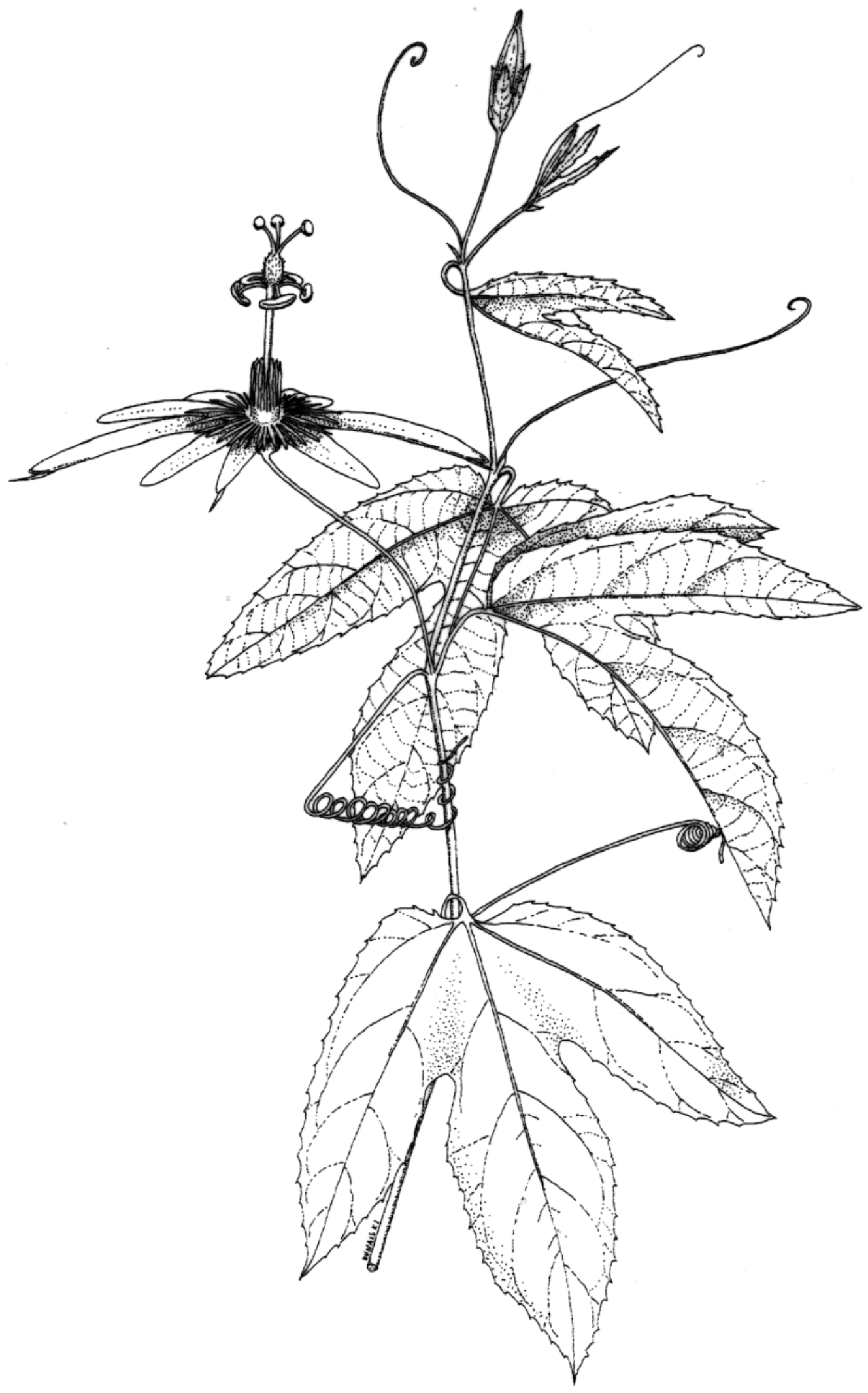

Figura 4. Passiflora quadriglandulosa Rodschied.: Hábito. Leg. D. G. Ca mpbell 20816;J.C.Ongley \& J. F. Ramos, 22/3/74. Amazpnas.Manaus - Porto Velho.Rio Tupana (NY;UPCB). 
Material examinado: Amazonas: Capoeiras, Leg. Spruce 1789 in VIII/1851 (K, P, BM); Manaus, Leg. Joubert, s/n in 1877/78 (P); Manaus à Itacoatiara, Leg. W. Rodrigues 8940, 17/9/70 (INPA, MBM); Manaus - Itacoatiacra, Leg. G. T. Prance 4921 et al., 30/5/68 (US, INPA, NY, K, P); Manaus, Praia de Lajes, Leg. G. Eiten 5117 et al.,, 22/ 1/ 63 (US); Barra, Leg. Spruce 1616, VI/1851 (P, $\mathrm{K})$; Manaus, Leg. M. Labroy 23 in 1906 (P); Rio Solimões, Leg. B.A. Krukoff 4504, 14/5/33 (G, M, $\mathrm{K})$; Rio Negro, Leg. E. Ule 5112, VII/1900 (G); Manaus, Leg. E. From 1359, et al., 21/1/63 (PACA); Rio Urubu, Leg. G.T. Prance 4921, 30/5/68 (K, NY); Rio Purus, Leg. G. Gottsberger \& J. Doring 21-4286, 4/2/96 (ULM, UPCB); Rio Tupana, km 160, Leg. D.G. Campbell P20816 et alii, (NY, UPCB, K, US, R).Manaus, Leg. E. P. Killip \& A, C, Smith 30002 et 30096, 13/10/29 (US); Rio Solimões, Leg. B. A. Kukroff 4504 (US); Pará: Almerim, Leg. A. Ducke 17335, 1/5/23 (RB, US); Pedras, Leg. G. A. Bach 57-19474, 24/5/57 et 57-19541, 24/5/57 (IAN); Onximiná, Rio Trombetas, Leg. C. A.Cid 1713 et al., 22/7/80 (UPCB). Rio de Janeiro: Quinta de São Cristovão, Leg. Glaziou 9851, 12/7/1877 cultivada $(\mathrm{P}, \mathrm{K})$.

Distribuição geográfica: Espécie restrita ao norte do Brasil: Amazonas e Pará. Foi cultivada no Rio de Janeiro por Glaziou em 1877.

Dados fenológicos: Floresce de maio a julho e frutifica de julho a outubro.

Observações ecológicas: Espécie de ramos vigorosos, heliófita. Quando encontrada no interior da floresta, seus ramos expandem até atingir as copas das árvores para florescer. Desenvolve-se muito bem na orla da floresta e capoeirões. Os frutos possuem um arilo doce e muito apreciado pelos pássaros, morcegos e pelo homem.

Etimologia: Por apresentar quatro glândulas no pecíolo foliar.
Observação: Passiflora quadriglandulosa pode ser confundida com Passiflora involucrata e Passiflora speciosa. Diferencia-se de P. involucrata pelo tamanho das brácteas e pela estrutura da corona de filamentos; de Passiflora speciosa pela estrutura da corona de filamentos. Acreditamos que esta espécie poderia ser cultivada para fins comerciais, pois seus frutos apresentam uma polpa doce e muito aromática. Observamos que em cidades no interior do Amazonas, os frutos desta espécie são comercializados pelo povo ribeirinho.

Passiflora speciosa Gardner in Fielding and Gardn. Sert. Pl. pl. 17. 1844.

Tipo: Brasil: Rio de Janeiro, Serra dos Orgãos, Leg. Gardner 426 (BM, Holótipo!; G, Isótipo!)

Planta trepadeira tomentosa ferrugínea, caule cilíndrico, estriado. Estípulas setáceas de 4-5 mm compr. decíduas. Pecíolos 1,5-2cm compr. com 4 glândulas. Folhas simples, trilobadas; lobulos linear-oblongos a ovalado-oblongos, raramente lineares de 4-12 x 0,7-5cm; ápice abtuso, agudo ou acuminado; margens simples ou duplamente crenado-denticuladas, arredondadas, subtruncadas ou cordadas na base, membranáceas. Pedúnculo de 7-12cm compr. Brácteas oblongas de 3,5-4 x 0,8-1cm, ápice agudo, com 2-4 glândulas conspícuas na base, margem glandular-serrada. Flores vermelhas, brilhantes ou escarlates. Tubo do cálice cilíndrico campanulado 7-10 x 0,8mm. Sépalas oblongas de 4-5 x 0,8-1,3cm, ápice obtuso, levemente carinadas; a quilha terminando em uma anista foliácea de 3-5mm compr. Pétalas oblongolanceoladas de tamanho igual as sépalas. Corona de filamentos em 2 séries; a série exterior de filamentos em forma de sovela de $1,5 \mathrm{~cm}$ compr. bandeados de púrpura e branco; a série interior filamentos de $0,8 \mathrm{~cm}$ compr. Opérculo pendente e a margem recurvada, crenulada ou denticulada na margem Ovário ovóideo, seríceo viloso. Fruto ovóide de 6 x 2,5cm diâmetro, viloso. Sementes de 5 x 3mm, levemente reticuladas. Icon.: Fig. 5. 


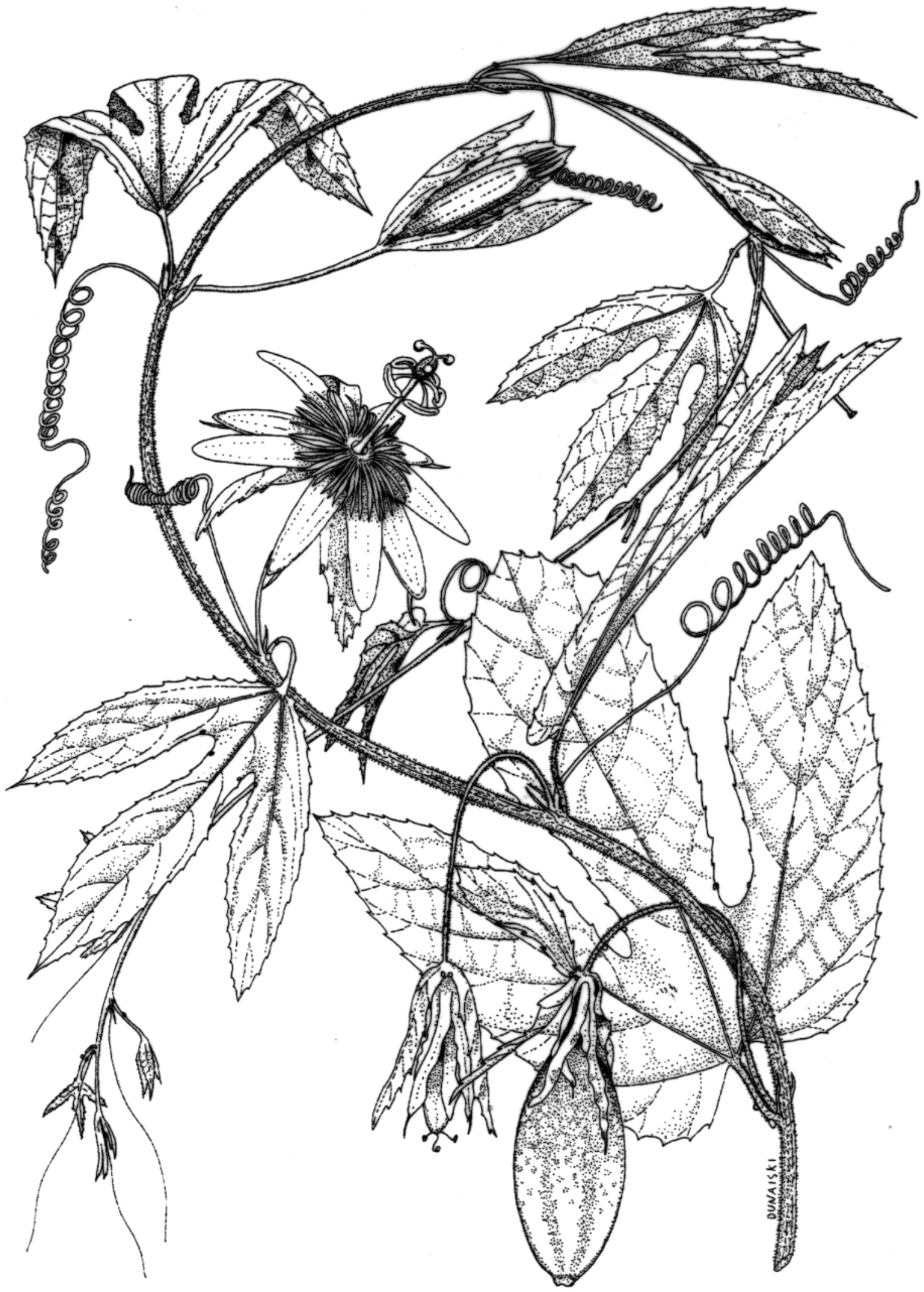

Figura 5. Passiflora speciosa Gardner: Hábito. Leg. G. Hatschbach 57924; A. C.Cervi \& J.M. Silva.10/ 10/92. Minas Gerais. Leopoldina. Rio das Pombas.( MBM; UPCB). 
Material examinado: Brasil: Mato Grosso: Cocaes, Leg. Gardner 4691, VIII/1840 (BM, K); Mato Grosso do Sul: Miranda, Passo do Lontra, Leg. V.M. Resende 376 et al., 29/12/90 (CG-MS); Minas Gerais: Leg. Saint Hilaire 282 et 590, in 1816/21 (P); Leg. Glaussen 379 et 380 in 1838 (G, P); Serro, Santo Antonio Itambé, Leg. G. Hatschbach 27500, 9/9/72 (MBM); Serra Azul de Minas para Rio Vermelho Leg. G. Hatschbach 67403 et al., 22/ 11/97 (MBM); Alfredo Chaves, São Bento da Urânia, Leg. G. Hatschbach \& J. M. Silva 61156,8/10/94 (MBM); João Monlevade, Leg. P.H.A. Pequeno 07 et al., 14/9/89 (MBM) Viçosa, Leg. Y. Mexia 4138, 19/12/29 (G, K, P,US); Viçosa, Fazenda Cresciúma, Leg.Y. Mexia 4795, 25/1/30 (P, G, US); Viçosa, Leg. L Emydio 1305, 6/9/57 (R); Viçosa, Leg. A. Chase 10201 et 10216, 15/11/29 (US); Leopoldina, Santa Izabel, Leg. M. Barreto 875, 8/6/33 (R); Leopoldina, Rio das Pombas, Leg. G. Hatschbach \& A. C. Cervi 57924, 10/10/92 (MBM, UPCB); Tombos, Leg. M. Barreto 1522,10/7/35 (R, US); Serra Piedade Leg. Palacios 3946 et al., 28/12/48 (R); Francisco Paulo, Leg. L. Araujo s/n, 1/12/83 (R); São Paulo Muriaé, Leg. A Mello s/n, I/1880 (R); Dionisio, Leg. E. Tameirão Neto 842, 26/7/92 (BHCB, UPCB); Marlieria, Parque Estadual do Rio Doce, Leg. J. A. Lombardi 1218 et al., 31/3/96 (BHCB, UPCB); Santa Barbara, Serra da Caraça, Leg. J. R. Stehmann 28426 et al., 11/9/90 (BHCB, UPCB); Santa Barbara, Serra da Caraça, Leg. M. Barreto 887, 14/4/33 (US); Leopoldina, Santa Izabel, Fazenda Nyagara, Leg. M. Barreto 885, 8/6/33 (US); São João Nepomuceno, Leg. L Krieger 16758, 26/10/79 (UPCB); Espírito Santo: Santa Tereza, Leg. H.Q. Boudet Fernandes 1515,18/9/85 (MBML, UPCB); Santa Leopoldina, Caioaba, Leg. W. Pizziolo 154, 4/8/84 (MBML, UPCB, MBM); Muniz Freire, Leg. G. Hatschbach \& O. Guimarães 46871, 15/10/ 83 (MBM); Santa Tereza, Volsugana Velha, Leg. H.Q. Bouded Fernandes 2592, (MBML; UPCB); Santa Tereza, Estação Biológica Santa Lucia, Leg. H. Q. Boudet Fernandes, 1616, 7/11/85 (MBML, UPCB); Rio Pancas, Aldeiamento dos Indios, Leg. E. A. Bueno 184, 8/ 7/42 (R). Vila Velha, Leg. Weimberg, s/n, s/d (R). Conceição do Castelo, Leg. G. Hatschbach \& J.M. Silva 49921, 18/10/ 85 (MBM); Rio de Janeiro: Leg. R.J.Miers s/n, 24/12/1837 (BM); Serra dos Orgãos, Leg. Gardner 426 in 1837 (BM, Lectótipo; G, Isolectótipo, $\mathrm{K}$, Isolectótipo); Terezepolis, Leg. Glaziopu 1598, 7/101867 (BR, P, R); Terezópolis, Quebra-Frasco, Leg. Brade 9693, 14/10/29 (R);
Canta Galo, Leg. L. Emydio 5270, 8/12/79 (R); Canta Galo, Leg. Peckolt 396 in 1860 (BR).

Distribuição geográfica: Esta espécie está restrita ao Sudoeste e Centro Oeste do Brasil nos seguintes estados: Mato Grosso, Mato Grosso do Sul, Minas Gerais, Espírito Santo e Rio de Janeiro.

Dados fenológicos: Floresce de agosto a dezembro e frutifica de dezembro a março.

Observações ecológicas: Espécie heliófita que se desenvolve muito bem na orla da floresta, capoeiras e capoeirões. Seus frutos são muito apreciados pelos pássaros, morcegos e o homem.

Etimologia: Do Latim speciosus, a, um = de belo aspecto; de aparência brilhante, elegante. Por apresentar as flores grandes, vistosas e de um vermelho brilhante escarlate.

Observação: Passiflora speciosa é muito semelhante à Passiflora vitifolia, diferencia-se pela estrutura da corona de filamentos, pois esta apresenta 3 séries e aquela 2 séries. Também pela distribuição geográfica, pois Passiflora speciosa tem ocorrência tão somente no Centro Oeste e Sudoeste e Passiflora vitifolia tem ocorrência somente na região Norte mais precisamente no estado do Amazonas.

Passiflora tholozanii Sacco in Ann. XV Congr. Soc. Bot. do Brasil 1:151. Fig.1. 1967.

Tipo: Brasil: Amazonas: Manaus, estrada Manaus - Itacoatiara, Leg. J. C. Sacco 1661 et al., 23/1/63 (PEL, Holótipo)

Planta trepadeira, caule cilíndrico, estriado, ferrugíneo tomentoso nas partes jovens. Estípulas de 0,7-1,5cm compr., lineares, ferrugíneotomentosas e com glândulas nas margens. Pecíolos de 1,5-3cm compr. com 2-4 glândulas sésseis na base da lâmina foliar. Folhas simples, inteiras, ovalelípticas de 6-15 x 3-10cm, membranáceas; ápice acuminado e base atenuada à sub-cordada; ferrugíneo-tomentosas na face abaxial e lustrosas na face adaxial, margens denteadas. Pedúnculos robustos de 6,5-11cm comp. Brácteas oval-elípticas de 3-6,3 x 1-2,8cm; base cuneada e ápice agudo mucronado, e de margem glândular-serreadas. Tubo 
do cálice cilíndrico-campanulado, sulcado de 0,9$1 \mathrm{~cm}$ compr.x 1,3-1,5cm de diâmetro. Sépalas oblongas, côncavas vermelhas lustrosas de 3-5 x 1-1,3cm. Pétalas de tamanho e cor igual as sépalas. Corona de filamentos em 2 séries, a série externa de filamentos subulados de 1-1,7cm compr., livres desde a base; a série interior, formada de filamentos filiformes de 0,5-0,8cm compr. Opérculo pendente de ápice recurvo fimbriado. Limem anular, róseo. Ovário ovalado a fusiforme, levemente trisulcado, viloso-tomentoso. Fruto globoso. Sementes obovadas de 5-6 x 4-4,2 $\mathrm{mm}$, levemente reticuladas. Icon.: Fig. 6.

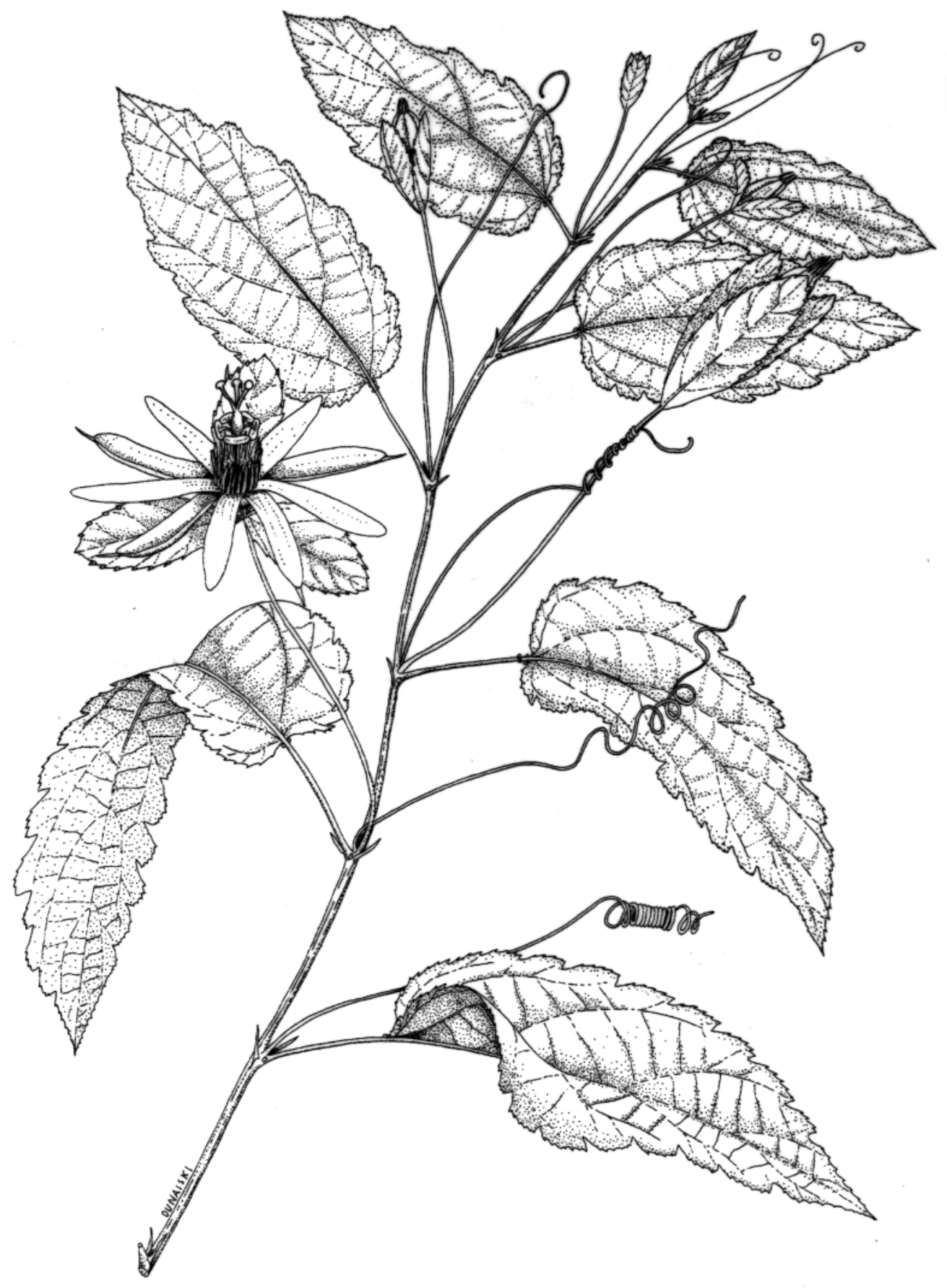

Figura 6. Passiflora tholozanii Sacco: Hábito. Leg. G. Hatschbach 11369, 3/9/64. Amazonas.Manaus. Estrada para Itacoatiara. (MBM; UPCB). 
Material examinado: Amazonas: Manaus - Itacoatiara, km 90, Rio Preto, Leg. W. Rodrigues \& J. Chagas 3016 (INPA, Parátipo); Manaus Itacoatiara, Rio Urubu, Leg. G. T. Prance 4922 et al., 30/5/68 (INPA, NY, US, P, K); Manaus, Uypiranga, Leg. A. Ducke s/n, 22/5/32 (RB, Parátipo); Manaus, Leg. A. Schultz 3155, I/63 (ICN, Parátipo); Rio Umbu, Leg. R.L Fróes 25492, 5/10/ 49 (RB, Parátipo); Manaus à Humaitá, Leg. S.R. Lowrie 6 et al., 16/9/80 (R); Maues, Fazenda de Francisco Merheri, Leg. D.G. Campbell P22032 et al., s/d, (NY, K, R, P, UPCB); Rio Purus, Lago Preto, Leg. G.T. Prance 13661 et al., 25/6/71 (NY, K, P, R, G, UPCB); Manaus - Itacotiara, Leg. G. Hatschbach 11369, 3/9/64 (MBM, UPCB); Rio Juruá, Leg. E. Ule 5555, VI/01 (G); Pará: Benfica, Zona Bragantina, Leg. A. D. Dtevens \& M. Tillery-Stevens 2463, 10/10/94 (ULM, UPCB); Amapá: Oiapoque, Clevalândia, Leg. W.E. Egler 1411, 25/4/60 (INPA); Mato Grosso: Barão de Capanema, Leg. F. C. Hoehne 2100, VI/09 (R).

Distribuição geográfica: Brasil: Amazonas, Pará, Amapá e Mato Grosso.

Dados fenológicos: Floresce de agosto a novembro e frutifica de novembro a fevereiro.

Observações ecológicas: Ecologicamente se comporta como Passiflora araujoi. Espécie heliófita que se desenvolve muito bem na orla da floresta, capoeiras e capoeirões.

Etimologia: Espécie dedicada ao Prof. Paulo Tholozan Dias da Costa, Diretor do Instituto de Pesquisas e Experimentação Agropecuárias do Sul e Catedrático da Cadeira de Economia Rural da Escola de Agronomia Elizeu Maciel, Pelotas, Rio Grande do Sul.

Observação: Passiflora tholozanii é semelhante a Passiflora araujoi e Passiflora coccinea. Distingue-se de Passiflora coccinea pela estrutura da corona de filamentos, que nesta apresenta a série interna unidas por uma membrana na base. De Passiflora araujoi por esta apresentar 3 séries de filamentos na corona enquanto Passiflora tholozanii apresenta somente 2 séries de filamentos na corona.

Passiflora variolata Poepp. \& Endl. in Nov. Gen. \& Sp. 2: 58. pl. 179. 1835.

Cieca variolata M. Roemer, Fam. Nat. Syn. 2: 140.1846.

Tipo: Brasil: Amazonas, Ega, Leg. Poeppig, s/n, s/d (W, Holótipo).

Planta trepadeira, glabra, com caule cilíndrico. Estípula linear, falcata, decídua. Pecíolo de $1 \mathrm{~cm}$ comp. com 2 glândulas sésseis na base da lâmina foliar. Folhas simples, inteiras, ovaladas a oblongas de $5-12 \mathrm{~cm}$ comp por $2-7 \mathrm{~cm}$ larg. agudas ou acuminadas no ápice, arredondadas ou subagudas na base, margem inteira, coriáceas, lustrosas na face adaxial. Pedúnculos solitários de 3$8 \mathrm{~cm}$ comp. Brácteas linear-lanceoladas de 8 x 1mm com glândulas (1 ou 2) na borda e base das brácteas. Flores vermelhas vistosas. Tubo do cálice campanulado e $7 \times 10 \mathrm{~mm}$ de diâmetro. Sépalas linear-oblongas de 3,5-4 x 0,7cm, ápices obtusos, carinadas, a quilha terminando em uma arista foliácea de 2-2,5mm de compr., margem com glândulas sésseis de aproximadamente $2 \mathrm{~mm}$ de larg. Pétalas de igual tamanho e cor das sépalas. Corona de filamentos em 2 séries; a série externa os filamentos estão disposto sobre uma membrana tubular; filamentos de 8-10mm compr.; a série interior de 2-3mm compr., membranáceos até a metade e filamentos lineares subulados na metade superior, clavados no ápice. Opérculo pendente de 4-5mm compr., denticulado na parte superior. Limem envolvendo a base do androginóforo; lacerado na margem. Ovário ovóide glabro. Fruto ovóide de 4 x 2,5 cm, verdes com pequenas manchas alvas. Icon.: Fig. 7. 


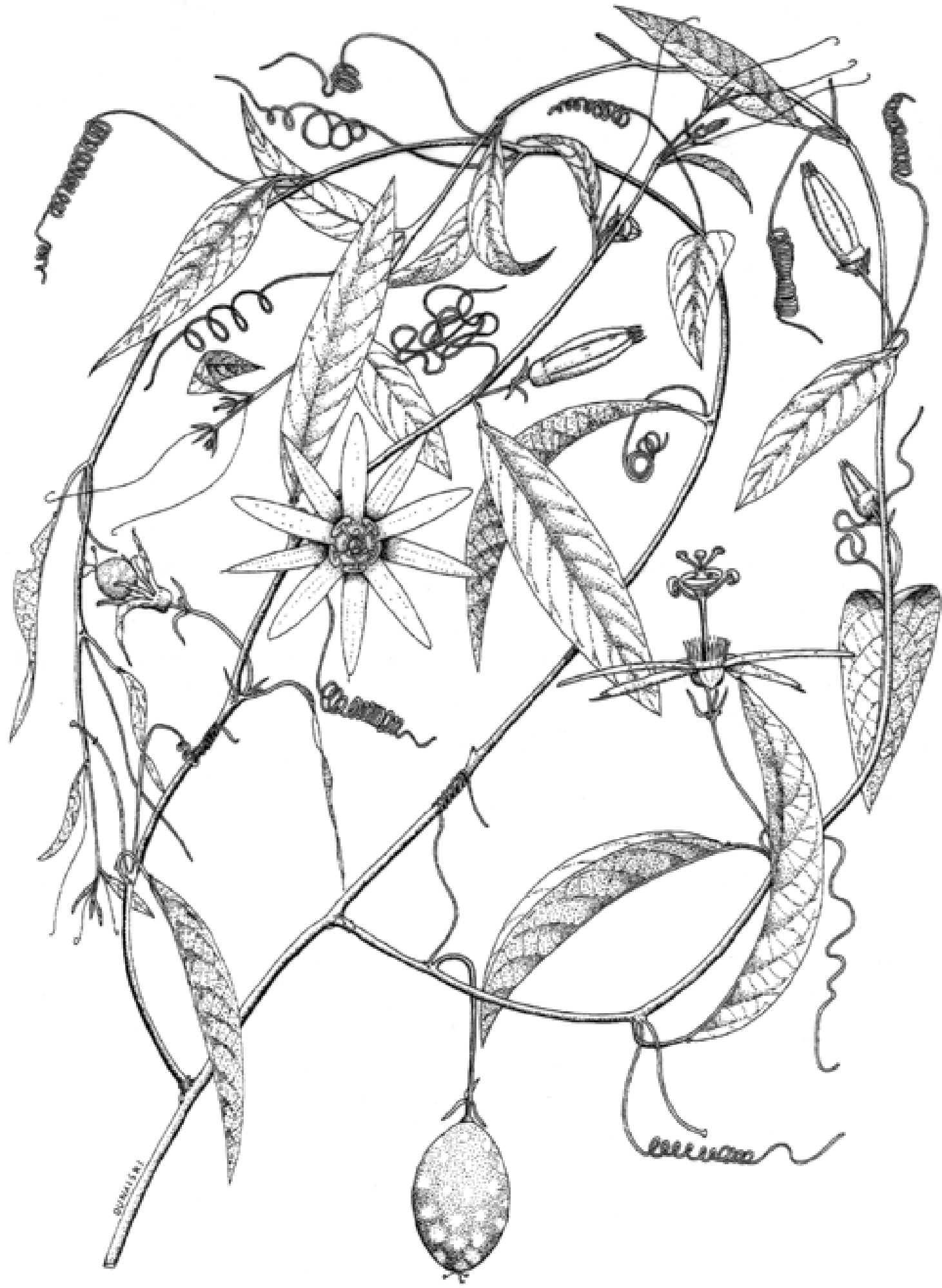

Figura 7. Passiflora variolata Poep.\& Endl. : Hábito. Leg. M. Emmerich 5926 et al. 21/7/86. Ma to Grosso. Vilhena. Posto Fiscal. Vila bela da Santíssima Trindade.(R; UPCB). 
Material examinado: Amazonas: São Gabriel, Leg. Spruce 2247, IV/ 1853 (K, US, 1 flor somente); São Gabriel, Rio Negro, Leg. A. Ducke 24042, 27/10/32 (RB, US) Panuré, Leg. Spruce 2868, I/1857 $(\mathrm{P}, \mathrm{K})$; Pará: Rodovia Belém-Brasília, km 249-254, Leg. E. Oliveira 874, 7/7/60 (IAN); Rodovia BelémBrasília, km 125-131 et km 344, Leg. E. Oliveira, s/n, 13/1/60 (IAN); Amapá: Rio Jari, Leg. N.T. Silva 2713, 19/8/69 (IAN); Rio Oiapoque, Estrada de Cricu, Leg. LY. Th. Westra 47318, 2/8/60 (IAN); Rondônia: Rio Madeira à Misenicórdia, Leg. G.T. Prance 6634 et al., 30/7/68 (K, US); Serra dos Pacaás-Novos, Leg. G.T. Prance 6670 et al., 1/8/68 (INPA, NY, K, US, P); Roraima: Boa Vista, Leg. J. A. Silva 485 et al., 30/7/ 86 (NY, UPCB); Mato Grosso: Vilhena, Posto Fiscal, Vila Bela da Santissima Trindade, Leg. M. Emmerich 5926 et al., 21/7/86 (R, UPCB).

Distribuição geográfica: Brasil: Amazonas, Pará, Amapá, Rondônia, Roraima e Mato Grosso.

Dados fenológicos: Floresce de julho a outubro e frutifica novembro a janeiro.

Observações ecológicas: Espécie heliófita e seletiva higrófita que ocorre no interior e orla da floresta, bem como em capoeira e capoeirões.

Etimologia: Do Latim varius, a, um, que é de várias cores, matizado. Provavelmente em relação aos frutos desta espécie, pois os mesmo são matizados de cores verde e branco.

Observação: Passiflora variolata assemelha se em muito com Passiflora gladulosa. Podese diferenciar P. variolata de P. glandulosa pela estrutura da corona de filamentos, pelas glândulas nectaríferas na margem das sépalas e pela localização das glândulas no pecíolo foliar.

Passiflora vitifolia Kunth in Nov. Gen. \& Sp. 2: 138. Fig. 1a. 1817.

Passiflora sanguinea J.E.Sm. in Rees. Cycl. 26: Passiflora No. 45. 1819.

Passiflora punicea Ruiz \& Pavon ex DC. Prodr. 3: 329. 1828. 1828.

Tacsonia sanguinea DC. Prodr.3. 334. 103. 1838.
Passiflora vitifolia var. cassiquiarensis M. Roemer, Fam. Nat. Syn. 2: 181. 1846.

Passiflora serrulata var. pubescens Griseb. Bonplandia 6: 7. 1858.

Passiflora servitensis Karst. Linnaea 30:

163. 1859

Tacsonia Buchanani Lemaire, Ill. Hort. 14: pl. 519. 1867.

Tipo: Colômbia, Magdalena, El Peñón, Leg. Humboldt \& Bonpland 1531 B, Holótipo destruído na Segunda Guerra Mundial).

Planta trepadeira com caule cilíndrico densamente tomentosa-ferrugínea. Estípulas setáceas de 3-5mm compr., decíduas. Pecíolo 2$5 \mathrm{~cm}$ compr. com 2 glândulas na base da lâmina foliar (ocasionalmente com 5 glândulas, sendo duas na base e 3 na metade do pecíolo), glândulas orbiculares. Folhas simples, trilobadas de 7-15 x 8$18 \mathrm{~cm}$, acuminadas no ápice e truncadas ou cordadas na base, 3-5 nervadas, margem irregularmente denteada ou crenada, membranáceas, lustrosas na face adaxial e densamente puberulentas ou tomentosas na face abaxial. Pedúnculo robusto de 4-9cm compr. Brácteas oblongas a oblongolanceoladas de 0,8-2,5 x 0,4-0,8cm, ápice acuminado e margem glândular-serreada, mais raramente subinteira. Flores escarlates ou vermelhas brilhantes. Tubo do cálice cilíndrico de $1-1,8 \mathrm{~cm} \mathrm{x}$ 1,5cm.. Sépalas carnosas, lanceoladas de 6-8 x 1$2 \mathrm{~cm}$, ápices obtusos, carinada, a quilha termina em uma arista foliar de aproximadamente $1 \mathrm{~cm}$ comp. Pétalas linear-lanceoladas de $4-6$ x 0,8-1,5 $\mathrm{cm}$. Corona de filamentos em 3 séries; a série externa filamentosa ereta de $2 \mathrm{~cm}$ de compr.; a série intermediária de filamentos eretos em forma de sovela de 1,5cm compr.; a série interna de $1 \mathrm{~cm}$ compr. constituída de uma membrana tubular circundando o androginóforo; o terço superior desta série divide-se em numerosos outros filamentos. Opérculo deflexo de 7-10mm compr. de margem fimbriada. Ovário elipsóidal, tomentoso. Fruto ovóide de $5 \times 3 \mathrm{~cm}$ de diâmetro, puberulento, aromático. Sementes obcordadas de $5 \times 3,5 \mathrm{~mm}$, reticuladas.

Material examinado: Amazonas: Manaus à Itacoatiara, Leg. G. T. Prance 4929 et al., 30/5/68 $(\mathrm{R}, \mathrm{K}, \mathrm{NY})$. 
Distribuição geográfica: Brasil: Amazonas.

Dados fenológicos: Foi examinada somente uma exsicata do Brasil, porém examinamos muito material exsicatado da Colômbia, Venezuela, Peru, Bolívia, Equador, Guiana Francesa, Panamá e Costa Rica, acreditamos que esta espécie floresce de maio a setembro e frutifica de setembro a dezembro.

Observações ecológicas: Espécie heliófita que ocorre na orla da floresta, bem como em capoeira e capoeirões.

Etimologia: Por suas folhas serem semelhantes à videira (Vitis vinifera L).

Observação: É a primeira citação desta espécie para o Brasil. Passiflora vitifolia é muito comum na Venezuela, Bolívia, Colômbia, Peru, Equador, Guiana Francesa, Panamá e Costa Rica.

\section{Agra decimentos}

Este trabalho é uma homenagem a minha linda e querida neta Maria Francisca Cervi Sigel que veio ao mundo no dia 5 de setembro de 2004.

\section{Referências}

BRUMMITT, R. K.; POWELL, C. E. Authors of plant names. New York: Royal Botanical Garden, 1992.

CERVI, A. C. Revisión del género Passiflora (Passifloraceae) del Estado do Paraná - Brasil. Univ. de Barcelona, Espanha 1981. 241p.

.; BIDÁ, A. Redescrição de Passiflora setulosa Killip. Collectanea Botánica, Barcelona, v.14, p. 247-251, 1983.

. Passifloraceae. Flora do Estado de Goiás Ed. Univ. Fed. de Goiás:1986. p. 1-45 (Coleção Rizzo, 7)

Contribuição ao estudo das Passifloráceas Brasileiras. 0 subgênero Passiflora do gênero Passiflora nas regiões sul, sudeste e centro-oeste. Tese para Prof. Titular do Departamento de Botânica da UFPR, Curitiba, PR. 1991. 260p.

Studies in Brasilian Passifloraceae III. A new species of Passiflora. Brittonia v. 46, n 2, p. 144-146, 1994a.

. Passiflora hatschbachii Cervi, Nueva especie de Minas Gerais (Brasil). Fontqueria, v. 40, p. 45-47, 1994b.

Passifloraceae da região de Carangola, Minas Gerais, Brasil. Pabstia v. 7, p. 1-32, 1996.

- Passifloracaceae do Brasil: Estudo do gênero Passiflora L. subgênero Passiflora. Fontqueria, v. 45, p 1-92, 1997.

Passifloraceae in Prodromus Florae Matogrossensis, Betrona-Verlag, serie B, no 3, p.235-237 e p. 420-421. 1998.

DE CANDOLLE, A. P. Passifloraceae. In: DE CANDOLE, A. P. Prod. Syst. Nat. v. 3, p. 321338, 1828.

DUBS, B. Prodromus Florae Matogrossensis. Betrona-Verlag, series B, no 3, 444 p. 1998.

ESCOBAR, L. K. Flora de Colombia Passifloraceae. Univ. Nac. de Colombia. 1988. 138p.

GENTRY, A. H. Distributional Patterns and an Additional Species of the Passiflora vitifolia Complex: Amazonian Species Diversity Due to Edaphically Differentiated Communities. Plant Syst. Evol., v.137, p. 95-105, 1981.

HARMS, H. Passifloraceae. In: Engler und Prantl, Die Naturlichen Pflanzenfamilien. Leipzig. Verlag von Wilhelm Engelmann. V. 3(6a), p. 69-94, f. 25-32, 1894.

Passifloraceae. In. Engler und Prantl. Die Naturlichen Pflanzenfamilien. Leipzig. Verlag Wilhelm Engelmann. 2 ed., v. 2l, p. 470-507, f.217233, 1925.

Passifloraceae americanae novae. Notizblatt des. Bot. Gard. Berlin, v. 10, n. 98, p. 806-821, 1929.

HOLMGREN, P. K.; HOLMGREN, N.H.; BARNETT, L. C. Index herbariorum: part I: The herbaria of the world. 8 ed. New York: International Association for Plant Taxonomic, 1990. 
HO LM-NILSEN, L.B.; JORGENSEN, P. M.; LAWESSO N, J. E. Flora of Ecuador. 126. Passifloraceae. Gunnar Harling and Lennart Andersson ed., v. 31, p. 1-130. 1988.

KILLIP, E. P. New species of Passiflora from tropical America. Journ. Wash. Acad. Sci. v. 14, n. 5, p. 108-116, 1924.

. The American species of Passifloraceae.

Pub. Field Mus. Nat. Hist. Bot. ser., v.19, n. 1-2, p. 1-613, 1938.

. Supplemental notes on the America Species of Passifloraceae with descriptions of new species. Contr. E. S. Nat. Herb. v. 35, n. 1, p. 123, fig. 1-11, 1960.

LINNAEUS, C. Species Plantarum ed. v. 1, n. 2, p. 955-960, 1753.

MASTERS, M. T. Contributions to the Natural History of Passifloraceae. Trans. Linn. Soc. London, v. 27, p. 593-645, 1871.

. MASTERS, M. T. Passifloraceae In: Martius, Fl. Bras. 13(1):527-628, tab. 106-128. 1872.

MELCHIOR, R. Passifloraceae. In: MELCHIOR, R. Engler's Syllabus der Pflanzenfamiliem. Gerbauder Borntraeger, Berlim, v. 2, p. 329-330, fig.139, 1964.

MORI, S. A. et. al. Manual de manejo de herbário fanerogâmico. S.l., Centro de pesquisas do Cacau: CEPLAC. 1989.

SACCO, J. C. Passifloraceae. Flora Ilustrada do Rio Grande do Sul, Fasc. 4. Bol. Inst. Cienc. Nat. v. 12, p. 7-29, fig. 1-13, 1962.

. Contribuição ao estudo das Passifloraceae do Brasil II. Duas novas espécies de Passiflora. Sellowia, v. 18, n. 18, p.41-47, 1966.
. Contribuição ao estudo das Passifloraceae do Brasil III. Passiflora trintae Sacco n.sp. Sellowia, v. 20, n. 20, 21-25, 1968.

. Contribuição ao estudo das Passifloraceae do Brasil IV. Passiflora castelanosii Sacco sp. n. Bradea, v. 1, n. 32, p. 345-348, 1973.

. Passifloraceae. In: Reitz, R. ed. Flora Ilustrada Catarinense, Itajaí. 130 p. 1980.

ULMER, B.; ULMER T. Passionsblumen - Eine faszinierende Gattung. Laupenmühlen Druck ed., 384 p., 1997.

URIBE URIBE, L. Passifloraceae. In: Mutis, Flora de la Real Expedición Botànica del Nuevo Reino de Granada. Madrid, Ed. Cult. Hisp., v. 27, p. 1-100, 1955.

USTERI, A. Flora der Ungebung der Stadt São Paulo in Brasilien. Jena, p. 207, 1911.

VANDERPLANK, J. Passion Flowers. 2nd. MT, 1996a. p.224.

. VANDERPLANK, J. Passiflora quadrifaria (Passifloraceae) in: Curtis's Botanical Magazine, p. $63-69,1996 b$.

VELLOSO, J. M. C. Passiflora. In: Flora Fluminense. Icones 9:tab.70-74; texto1881.In: Arch. Mus. Nac., RJ., v. 5, p. 376-381, 1831.

WILDE, W. J. J. O. The genera of tribe Passiflora (Passifloraceae) with special reference to flower morphology. Blumea, v. 22, p. 37-50, 1974.

Recebido em/Recived in: 16.02.2004 Aprovado em/Approved in: 06.04.2004 